\title{
Organochlorine Pesticide Residues in Rice Paddies in Malaysia, 1981
}

\author{
Peter G. Meier, ${ }^{1}$ Donald Chen Fook, ${ }^{1}$ and Karl F. Lagler ${ }^{2}$ \\ 1Department of Environmental and Industrial Health, School of Public Health, \\ The University of Michigan, Ann Arbor, MI 48109, and 2 School of \\ Natural Resources, The University of Michigan, Ann Arbor, MI 48109
}

Rice and fish are common staple foods in many parts of Asia, Africa, and Latin America. The cultivation of fish in paddy fields has proven to be highly productive. Simultaneous rice and fish cultures can be accomplished with little extra effort and is economically feasible and practical. Fish enhance rice yield through predation of insect pests, reduce aquatic vascular plant and algal growth, and add nutrients through deposition of fecal matter (TAN et a1. 1973).

However, the present use of persistent and toxic pesticides in paddy fields may not only destroy the ecological relationship between rice and fish, but may even prove deleterious to the consumers. In order to assess the potential health implications to paddy farmers, this study was conducted to determine the indigenous concentrations of organochlorine pesticides in the paddy fish, sediment, and water.

\section{MATERIALS AND METHODS}

A total of 332 paddy fish was taken from five sampling locations in the Krian District, State of Perak, Malaysia, using a $6 \mathrm{~cm}$ square-mesh gill net, a cast net, and wire cage traps. The fish were pooled at each location with 36 at Tanjong Piandang (paddy field), 98 at Sungei Kota (paddy field), 83 at Jalan Bharu (sump pond), 59 at Parit Tanjong Piandang (irrigation/drainage canal), and 56 at Sungei Burong (irrigation/drainage canal). Each catch of fish was systematically divided into subsamples of $6,16,12,8$ and 8 for the respective locations. Each subsample was made up of 6 to $8 \mathrm{fish}$ for a composite of $500 \mathrm{~g}$. In addition, three composite samples of sediment and water were collected at each of the sampling locations.

Fish were washed, eviscerated, skinned, filleted, and homogenized in a high-speed blender with sodium sulfate added (4:1 sodium sulfate to tissue). Samples of approximately $10 \mathrm{~g}$ (wet weight) of fish, $5 \mathrm{~g}$ (wet weight) of sediment, and one liter of water were treated for extraction. Individual fish and sediment samples were extracted with hexane:acetone (100 $\mathrm{mL}$ each) in a Soxhlet extractor using a 24-h cycle. The water samples were extracted twice in a separatory funnel with $250 \mathrm{~mL}$ of hexane. 
Subsequently, all the treated samples were dried with $\mathrm{Na}_{2} \mathrm{SO}_{4}$ and concentrated.

The extracted samples were cleaned by eluting them through Florisil columns with three fractions of $50 \mathrm{~mL}$ petroleum ether $(\mathrm{PE}), 7.5 \mathrm{~mL}$ of acetone in $42.5 \mathrm{~mL} \mathrm{PE}$, and $25 \mathrm{~mL}$ of acetone in 25 $\mathrm{mL} P E$. The cleaned samples were then fractionized using silica gel columns ( $31.75 \mathrm{~cm} \times 12.75 \mathrm{~mm}$ i.d.) (SNYDER \& REINERT 1971) and fractions of $0.15 \%$ dichloromethane in $75 \mathrm{~mL}$ of hexane and $35 \mathrm{~mL}$ $100 \%$ dichloromethane. The first fraction usually contained PCB isomers, $p, p^{\prime}-D D T$, and traces of $\mathrm{HCH}$ isomers; whereas, the second fraction mainly consisted of organochlorine residues.

The final extracts were concentrated and analyzed prior and after acidification with conc. $\mathrm{H}_{2} \mathrm{SO}_{4}$ (1:10 with samples). The acid and the sample were mixed thoroughly in a test tube using a highspeed vortex mixer for about $1.5 \mathrm{~min}$ and allowed to settle for at least $30 \mathrm{~min}$. The acid oxidized any remaining contaminants such as phthalates (which often interfere with GC peaks of the organochlorine pesticides). Also, the acid treatment helped confirm the presence or absence of dieldrin residues, which were oxidized by the acid in the samples.

The chemical analyses were conducted using a dual column GC model Varian 3700, interfaced with a computerized model Varian CDS401 integrator. Column A packing consisted of a mixed phase of $1.5 \% \mathrm{SP}-2250 / 1.95 \mathrm{SP}-2401$ as the stationary phase on $100 / 120$ mesh Supelcoport glass column ( $2 \mathrm{~mm}$ i.d. $\times 1.8 \mathrm{~m})$. Column B packing consisted of a single phase 5\% SP-2100 on 100/120 mesh Supelcoport glass column $(2 \mathrm{~mm}$ i.d. $\times 1.8 \mathrm{~m})$. An electron-capture detector with pulsed $63 \mathrm{Ni}$ ECD was used. The operation temperatures for both injection ports were $220^{\circ} \mathrm{C}$; columns $A$ and $B$ were $190^{\circ} \mathrm{C}$; and the detector was $320^{\circ} \mathrm{C}$. The carrier gas was nitrogen with an adjusted flow rate at $45 \mathrm{~mL} / \mathrm{min}$ for column $B$ and $48 \mathrm{~mL} / \mathrm{min}$ for column $A$. Triplicate sample volumes of $4 \mu \mathrm{L}$ were injected into the $\mathrm{GC}$ for analysis. Resulting peaks were confirmed with EPA standards.

In conjunction with the environmental survey, an interview was carried out with 10 farming families at each collection site. This personal survey included several specific questions through which the respondent gave information as to the size of paddy field; number of crops per year; type, amount, and number of pesticide applications; and the frequency of fish collection and quantities consumed (CHEN 1982). Information derived from this interview was used to aid in the interpretation of the data.

\section{RESULTS AND DISCUSSION}

Among the different environmental samples analyzed, the residue levels in water were the lowest, except for aldrin which was higher than that observed in sediments from all sampling sites (Table 1). Variable concentrations of different pesticides in the water samples were a function of application time and pesticides employed. For the five sites sampled, the number of applications varied from 


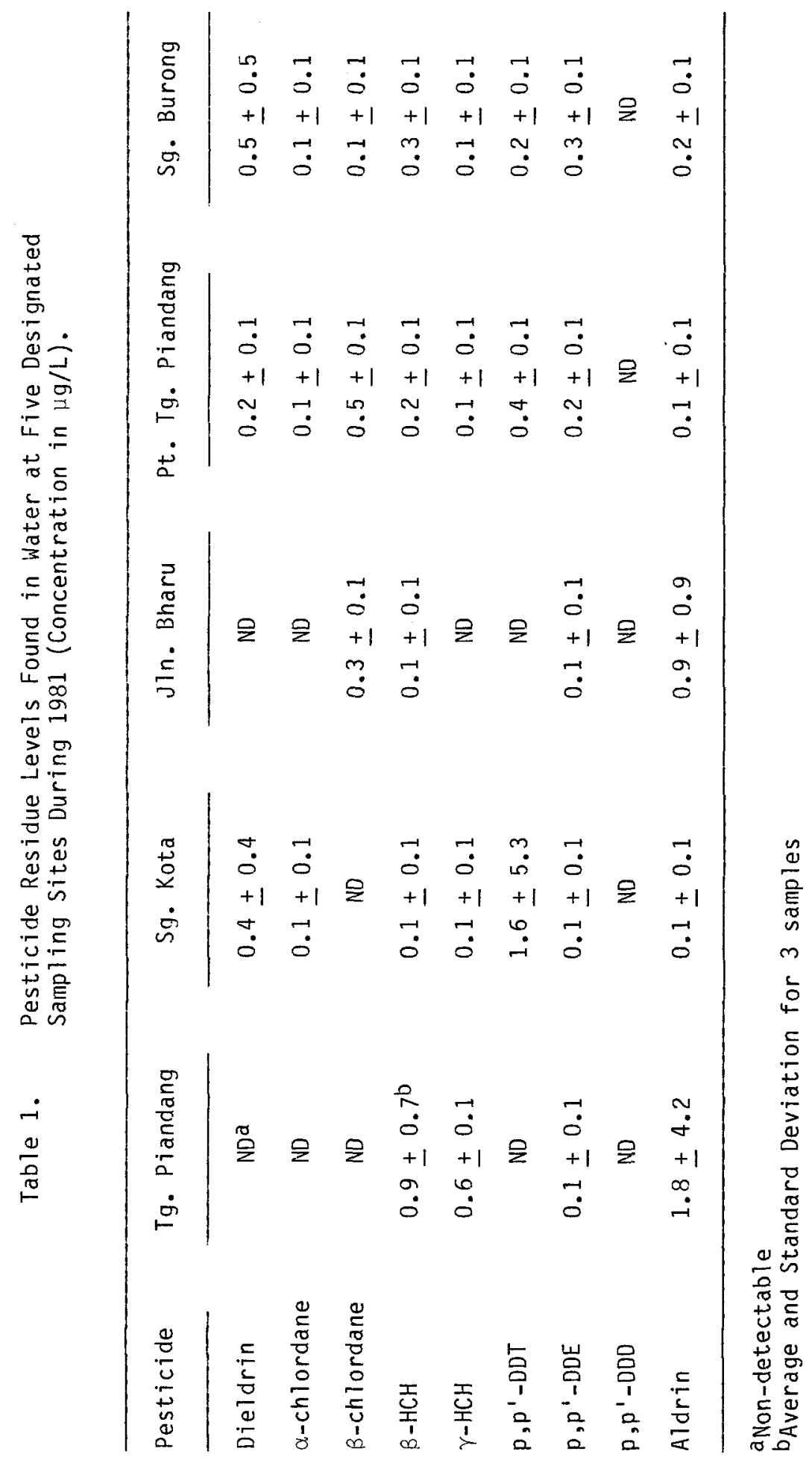


1 to 12 per year and the amount applied ranged from 1 to $6 \mathrm{~kg}$ per hectare.

Aquatic sediments also showed considerable variation in residue concentrations not only from the same site but between sites. Even though similar application rates with the same pesticide were used at Pt. Tg. Piandang and Jln. Bharu, the latter site had considerably higher concentrations of dieldrin, chlordane, BHC and $\mathbf{p}, p^{\prime}-$ DDT (Table 2). This phenomenon of variability of pesticide concentration in sediments does not only occur in Malaysia, but is a world-wide problem. The differences in composition and concentration of pesticide residues are attributed to numerous factors such as composition of sediments, pesticide treatment (spot versus total surface application), type of pesticide employed, and historical information (quantity and type of pesticide applied prior to 1981). Since this information was not available, data reported here are those of a comparative nature between sampling sites. Finally it can be stated that the residues found in sediments were similar in composition to those in fish, but at somewhat lower levels. The highest average concentrations were dieldrin (4.7 $\mathrm{ng} / \mathrm{g})$, chlordane $(6.6 \mathrm{ng} / \mathrm{g})$, $\mathrm{HCH}(\beta-7.96 \mathrm{ng} / \mathrm{g}$ and $\gamma-0.77$ $\mathrm{ng} / \mathrm{g})$, ¿DDT $(9.13 \mathrm{ng} / \mathrm{g})$, and aldrin $(0.13 \mathrm{ng} / \mathrm{g})$.

Fish collected from Tg. Piandang had the highest average pesticide residues (Table 3 ). The higher contamination was attributed to the fishes long residence time in the polluted environment. Interviews with resident farmers indicated that they collected fish only once a season, whereas at other sites fish were caught as frequently as twice a week. Fish consumption was variable and it ranged from $54 \mathrm{~g}$ per day at Pt. Piandang to $205 \mathrm{~g}$ per day at Pt. Tg. Piandang. It is fortunate that low fish consumption coincides with high residue levels. If this were not the case, rice paddy farmers at Tg. Piandang would be at some health risk.

The highest average concentration of pesticides in fish were dieldrin $(24.9 \mathrm{ng} / \mathrm{g})$, chlordane $(27.8 \mathrm{ng} / \mathrm{g}), \mathrm{HCH}(\beta-8.2 \mathrm{ng} / \mathrm{g}$ and $\gamma-3.5 \mathrm{ng} / \mathrm{g})$, and aldrin (1.1 ng/g). The observed levels were considerably lower than those presented by FRANK et al. (1978) of Lake Erie and St. Clair fish. Some of the mean residue concentrations in fish from Lake Erie were dieldrin $(190 \mathrm{ng} / \mathrm{g})$, chlordane (46 $\mathrm{ng} / \mathrm{g}$ ) and DDT $(560 \mathrm{ng} / \mathrm{g})$. Fish from Lake St. Clair had mean residue levels for dieldrin $(55 \mathrm{ng} / \mathrm{g})$, chlordane $(8 \mathrm{ng} / \mathrm{g}$ ) and DDT $190 \mathrm{ng} / \mathrm{g})$. It should be pointed out that a comparison between the U.S. survey (FRANK et al. 1978) and this study may not be valid due to the differences in species composition, age and fat content.

Although the levels determined in the paddy fish appear to be low as compared to those observed in the United States (FRANK et al. 1978), it should be stressed that these data are from fillets of fish that were exposed to a contaminated environment for less than 6 months. From these data it can be concluded that the paddy farmer is at risk through the consumption of large daily rations of fish which exceeds that quantity eaten by the average resident 


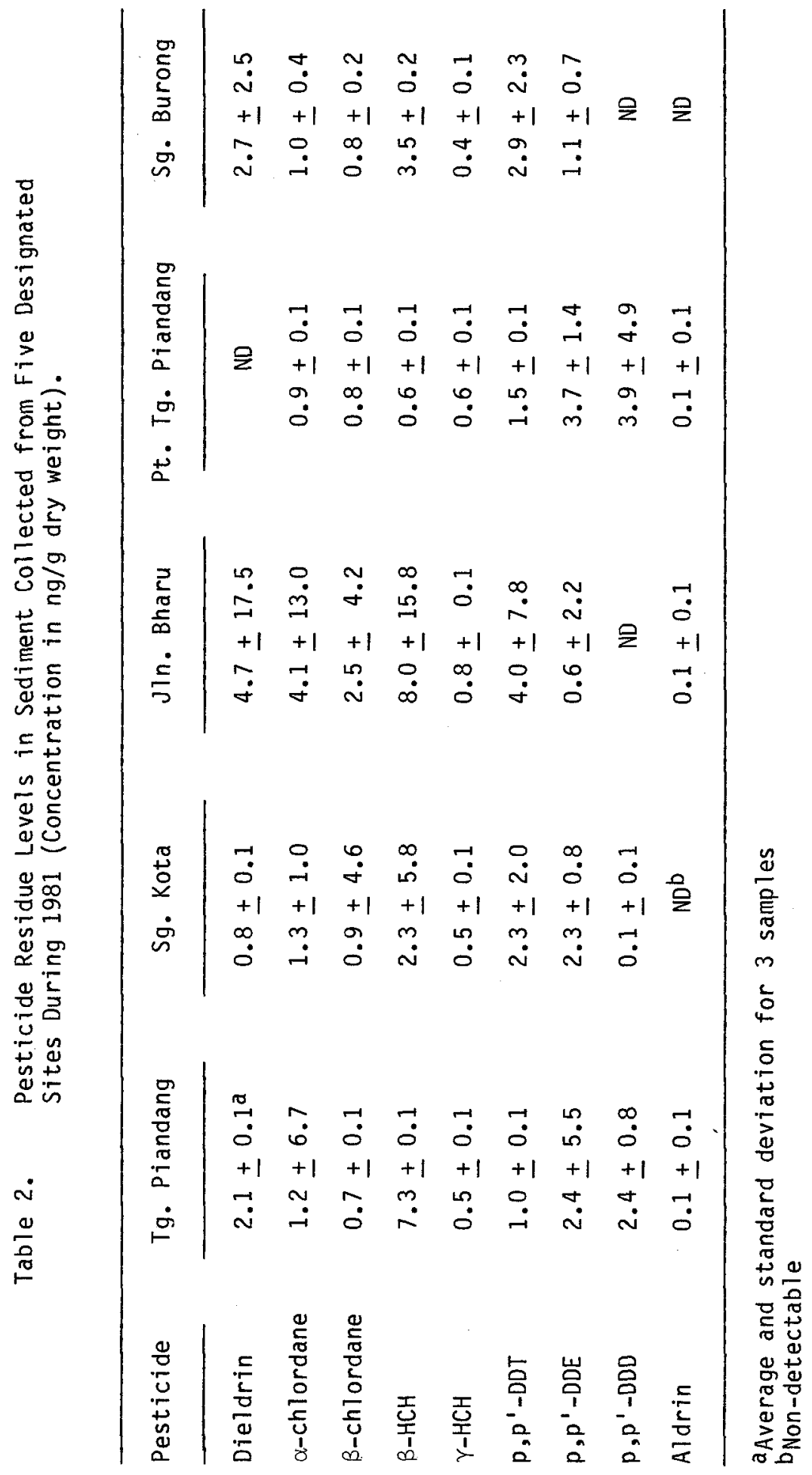




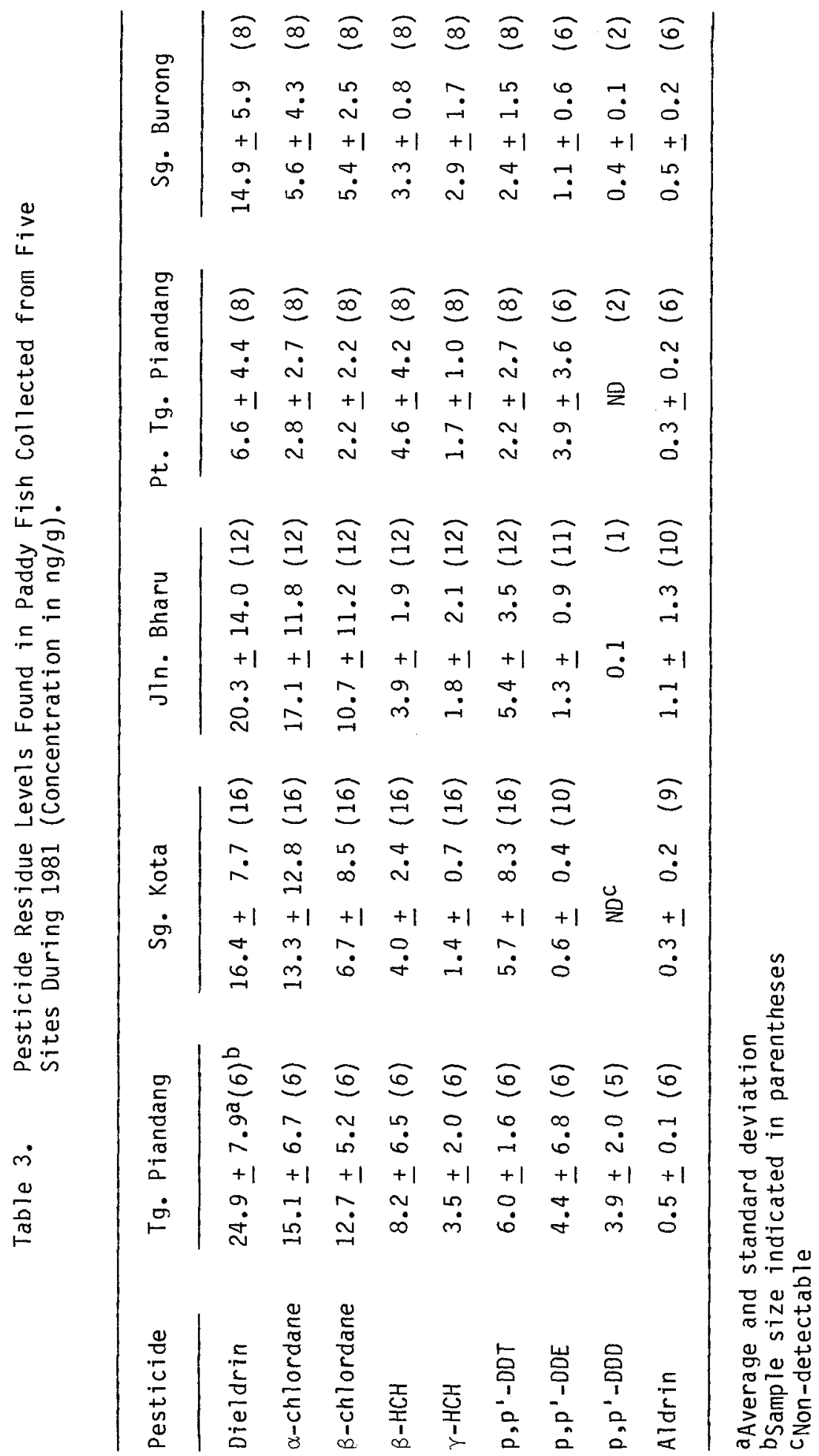


of the Great Lakes area (CHEN 1982). Hence, the lack of sufficient knowledge on actual concentrations of common pesticide residues in Malaysian rice paddy fishes by agencies (Department of Agriculture and Fisheries) prevents the dissemination of vital information to the population at risk. It is therefore recommended that a governmental sponsored monitoring program be established within the districts of Malaysia that would have the responsibility of determining the actual concentration of common pesticides not only in fish, but also in rice and other foods that make up the diet of a farmer. From these data, health risk assessment should be calculated and the results should be made available to the population at risk, namely the rice paddy farmers.

\section{ACKNOWLEDGEMENT}

This work was made possible through the cooperation of the agricultural officer at Kuala Kurau and respective rice paddy farmers. Use of instrumentation at The University of Michigan Great Lakes Research Division was greatly appreciated.

\section{REFERENCES}

CHEN, D.F.K.: Analysis of Organochlorine Pesticide Residues in Malaysian Paddy Fish and the Health Risk to Human Consumption. Doctoral Thesis, The University of Michigan (1982).

FRANK, R., HEIZU, E.B., HOLDRINET, M. DODGE, D.P. and S.J. NEPSZY: Pest. Monit. J. 12:69 (1978).

SNYDER, D. and R. REINERT: Bu11. Environ. Contam. Toxicol. 6:385 (1971).

TAN, C.E., CHONG, B.J., SIER, H.J. and T. MOULTON: Bull. No. 128. Ministry of Agri. and Fish., Malaysia (1973).

Accepted December 20, 1982 